\title{
EFSUMB Ultrasound Learning Centre Timisoara, Romania
}

The first EFSUMB Ultrasound Learning Centre (ULC) at the „Victor Babeş“ University of Medicine and Pharmacy Timişoara

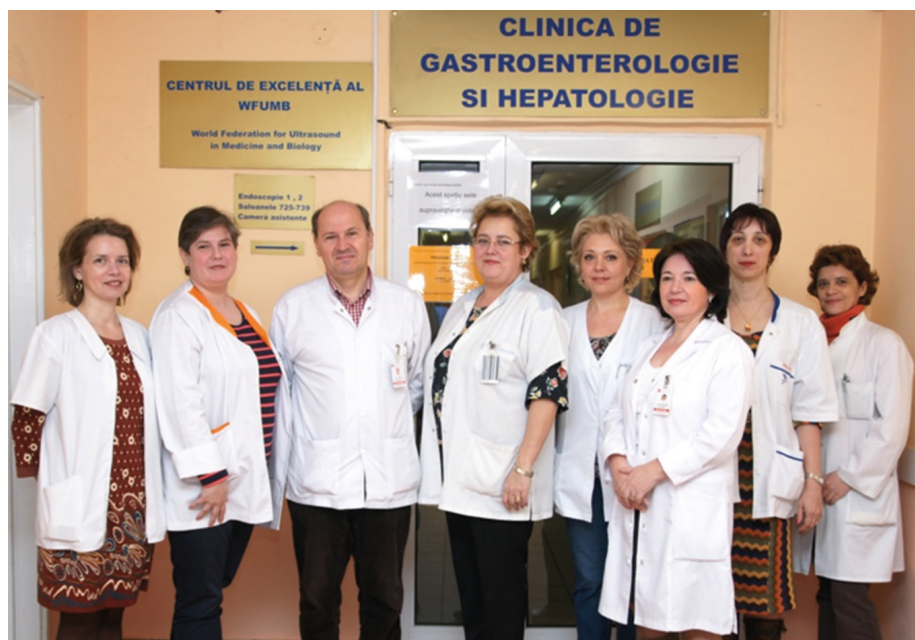

has been approved. The Course Director is Prof. Ioan Sporea, MD, PhD and Lecturer Alina Popescu, MD, PhD is Co-director.
Lecturer Roxana Şirli and Assist. Prof. Mirela Dănilă are also part of the faculty.

The object of ULC's is to offer participants a period of time spent learning about and improving their knowledge in various ap- plications of ultrasound. These centres are established in renowned ultrasound departments at universities, hospitals and in medical practices, led by respected ultrasound practitioners, and approved by EFSUMB. There is no charge for attending these Centres and a certificate may be awarded by a ULC as proof that the participant has achieved a particular standard in ultrasound learning. Teaching will usually be in English for a period of about 1 - 4 weeks and Centres may offer free accommodation and other limited assistance. This is entirely at the discretion of each Centre and will be advised on application.

Participants can expect to find all Centre's equipment listed on their website, including new technology, simulators, transducers, and the availability of ultrasound machines that allow practical hands-on training. Numbers will be limited to ensure a maximum of 6 participants for each available US machine per course. The EFSUMB Course Book on Ultrasound is intended to form a basis of knowledge and a manual of instruction to the course participants. We hope you will take advantage of this unparalleled opportunity to advance your ultrasound skills. 